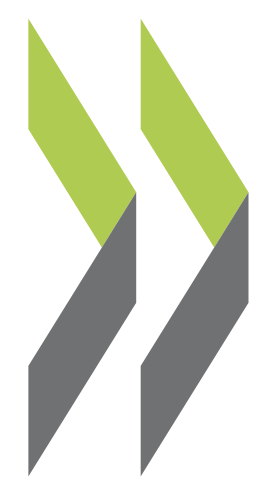

OECD Economics Department Working Papers No. 592

Solow or Lucas?: Testing Growth Models Using Panel Data from OECD Countries

\section{Jens Matthias Arnold,}

Andrea Bassanini, Stefano Scarpetta 
Organisation de Coopération et de Développement Economiques

ECONOMICS DEPARTMENT

SOLOW OR LUCAS?

TESTING GROWTH MODELS USING PANEL DATA FROM OECD COUNTRIES

ECONOMICS DEPARTMENT WORKING PAPERS No. 592

By

Jens Arnold, Andrea Bassanini and Stefano Scarpetta 


\section{ABSTRACT/RÉSUMÉ \\ Solow or Lucas? \\ Testing growth models using panel data from OECD countries}

In this paper, we test whether the growth experience of a sample of OECD countries over the past three decades is more consistent with the human-capital augmented Solow model of exogenous growth, or with an endogenous growth model à la Uzawa-Lucas with constant returns to scale to "broad" (human and physical) capital. We exploit the different non-linear restrictions implied by these two models to discriminate between them. Using pooled crosscountry time-series data, we specify our growth regression by imposing cross-country homogeneity restrictions only on long-run coefficients, while letting the speed of convergence and short term dynamics to vary across countries. While there are indeed good reasons to believe in common long-run coefficients, given that OECD countries have access to common technologies and have intensive intra-industry trade and foreign direct investment, the theoretical models imply that the speed of convergence to the steady state differs across countries because of cross-country heterogeneity in population growth, technical change and progressiveness of the income tax. Therefore, standard dynamic fixed effect specifications, by imposing cross-country homogeneity restrictions on speed of convergence and short-run parameters, suffer from a heterogeneity bias and are not suited to implement our tests. The results suggest a strong effect of human capital accumulation: the estimated long-run effect on output of one additional year of education (about 6-9\%) is also within the range of the estimates obtained in microeconomic analyses of the private returns to schooling. Our estimated speed of convergence is too fast to be compatible with the augmented Solow model, while is consistent with the Uzawa-Lucas model with constant returns to scale. This main finding is robust to several robustness tests.

JEL classification: O11, O15, O41

Keywords: growth, human capital, panel data

$* * * * * * * * * * * * * * * * * * *$

Solow ou Lucas?

\section{Un test des modèles de croissance basé sur des données en panel pour les pays de l'OCDE}

Dans cet article nous analysons le processus de croissance dans un groupe de pays de l'OCDE au cours des trois dernières décennies. Nous cherchons à établir si ce processus est plus conforme à un modèle de croissance exogène à la Solow ou bien à un modèle de croissance endogène à la Uzawa-Lucas avec des rendements d'échelle constants par rapport au capital au sens large (humain et physique). Pour cela, nous exploitons les contraintes non-linéaires propres aux deux modèles et nous étudions leur conformité avec les données. En utilisant des données de panel, nous spécifions une équation de croissance dans laquelle les paramètres de court terme et la vitesse de convergence varient d'un pays à l'autre, alors que seuls les paramètres de long terme sont supposés communs. Alors qu'il y a de bonnes raisons pour faire l'hypothèse que les coefficients à long terme sont égaux entre les pays de l'OCDE qui ont accès aux mêmes technologies et ont des relations commerciales étroites, les deux modèles théoriques suggèrent que la vitesse de convergence devrait différer selon les pays en raison de différences dans le taux de croissance de la population, le progrès technique et le taux de progressivité des impôts. Dans ces conditions, les spécifications dynamiques standard à effets fixes qui imposent l'homogénéité de tous les paramètres souffrent d'un biais et ne sont pas valables pour notre test des deux modèles. Nos résultats suggèrent un impact positif et significatif de l'accumulation du capital humain sur la croissance de la production par tête : une année supplémentaire de niveau moyen d'études dans un pays aurait un effet positif à long terme sur la production (de 6-9\%), ce qui est en accord avec l'évidence microéconomique sur le taux de rendement privé de l'investissement en éducation. La vitesse de convergence estimée est trop rapide pour être compatible avec le modèle de Solow. En revanche, nos résultats sont compatibles avec un modèle de Uzawa-Lucas avec des rendements d'échelle constants. Ce résultat principal est confirmé par des tests de robustesse.

Classification JEL : O11, O15, O41

Mots-Clés : croissance, capital humain, données de panel

Copyright OECD 2007

Application for permission to reproduce or translate all, or part of, this material should be made to: Head of Publications Service, OECD, 2 rue André-Pascal, 75775 Paris Cedex 16, France. 
TABLE OF CONTENTS

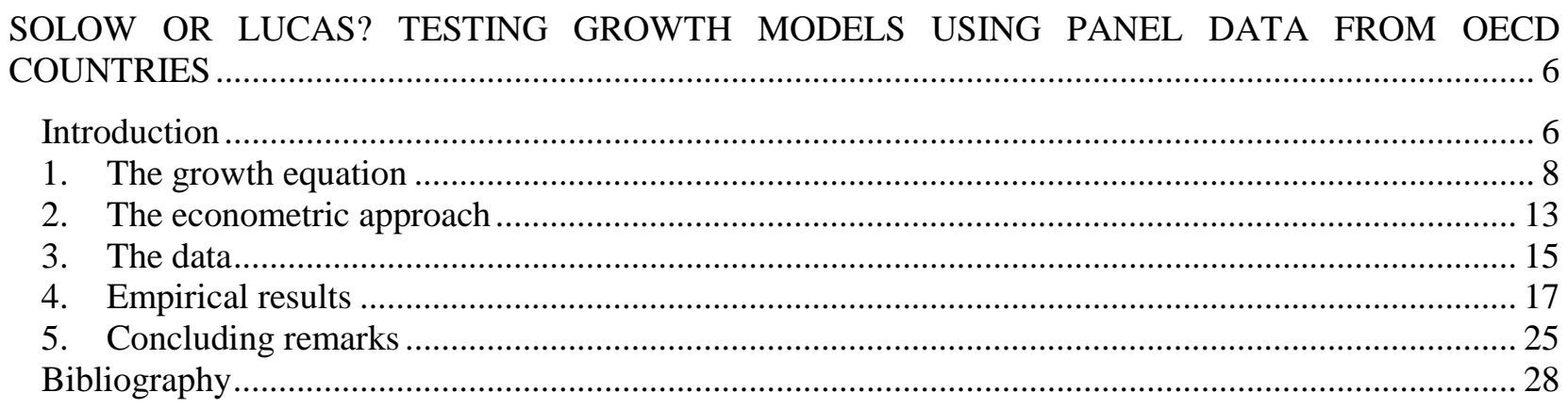

\section{Tables}

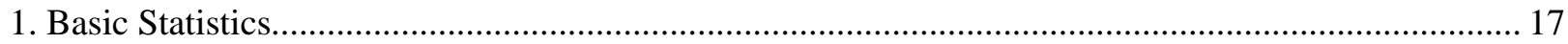

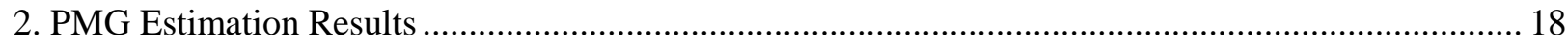

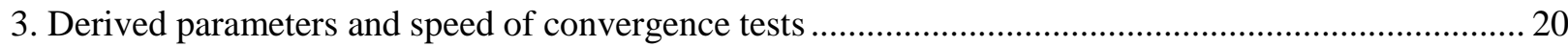

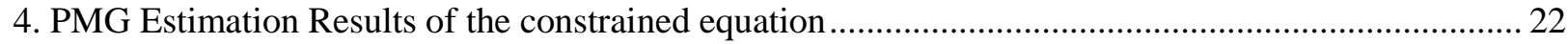

5. Difference GMM-MG Estimation Results of the constrained equation............................................... 24

A.1. Average years of education of the population aged 25-64 ......................................................... 26 


\section{ECO/WKP(2007)52}


ECO/WKP(2007)52

\title{
SOLOW OR LUCAS? TESTING GROWTH MODELS USING PANEL DATA FROM OECD COUNTRIES ${ }^{1}$
}

\author{
Jens Arnold ${ }^{2}$, Andrea Bassanini ${ }^{3}$ and Stefano Scarpetta ${ }^{4}$
}

\section{Introduction}

In the recent empirical literature, a consensus is emerging that the accumulation of human capital is a fundamental factor determining output growth. Micro-econometric studies based on Mincerian human capital earnings functions suggest significant private returns to education: one additional year of schooling is invariably associated with between 5 and $15 \%$ higher earnings across a wide range of countries (Card, 1999, Psacharopoulos and Patrinos, 2004). Growth accounting exercises (e.g. Jorgenson et al., 1987; Jorgenson and Stiroh, 2000) provide additional support to a significant growth impact of human capital accumulation (see also Topel, 1999). Finally, recent growth regressions studies based on improved methods and datasets appear to unambiguously point to a positive effect of human capital on output growth, although a lot of uncertainty remains on the magnitude of this effect (see Krueger and Lindahl, 2001, Sianesi and van Reenen, 2003 for recent surveys).

But does the enhancement of human capital have a permanent impact on growth? Or does it affect only the level of steady-state output with a growth effect only in the transitional dynamics towards the new steady-state growth path? In other words, what is the appropriate way to model the relationship between human capital and aggregate output? The two archetypes of growth models that have been more frequently considered in empirical growth applications are the Solow model and the AK model; the main the distinction between the two depending essentially on the hypothesis made on the production function (decreasing or constant returns to variable factors, respectively). The AK model implies a permanent effect of the investment rate on long-run growth, and growth is therefore endogenous, while in the Solow model the impact of the investment rate is only transitory, the only driver of growth being therefore exogenous technological change. When a distinction between physical and human capital is made, the natural extensions of these models are, respectively, the augmented Solow model (Mankiw et al., 1992) and the two-sector AK (or Uzawa-Lucas) model (Uzawa, 1965, Lucas, 1988). Consistently, in the latter the process

1. The opinions expressed in this paper are those of the authors and do not necessarily reflect those of the OECD. We thank Angel De la Fuente, Alain de Serres, Jorgen Elmeskov, Mike Feiner, Cecilia GarciaPeñalosa, Patrick Pintus and seminar participants at GREQAM (Marseille), Evry and OECD Economics Department for helpful comments, as well as Ed Blackburne and Mark Frank for making their Stata algorithms available to us before their official publication. All errors remain ours.

2. $\quad$ OECD Economics Department, E-mail: jens.arnold@oecd.org.

3. OECD Employment, Labour and Social Affairs Directorate and ERMES, Université Paris II. Address for correspondence: OECD, DELSA, 2 Rue André Pascal, 75775 Paris Cedex 16, France.

E-mail: andrea.bassanini@oecd.org .

4. OECD Economics Department and Institute for the Study of Labour (IZA).

E-mail: stefano.scarpetta@oecd.org. 
of accumulation of human capital is the main driver of growth, while in the former it has only a transitory impact on growth, permanently affecting only the level of the steady state.

In an influential paper, Jones (1995) finds no evidence of a permanent effect of the investment rate on growth. Since then, one and two-sector AK models have been abandoned in the empirical literature, with scholars usually resorting to either agnostic reduced-form specifications or the augmented Solow model (e.g. De la Fuente and Domenech., 2001), although often struggling with a too fast convergence rate (e.g. Bond et al., 2001). In recent years, several empirical papers have reconsidered the relationship between the investment rate and output growth and found evidence of a permanent effect of investment rate on economic growth, rejecting the Solow model (Bernanke and Gürkaynak, 2001, Li, 2002, Bond et al., 2004). However, Bond et al. (2004) do not consider human capital in their specifications. Bernanke and Gürkaynak (2001) assume that all countries are on their steady state, including developing countries, which is difficult to defend. Moreover, while rejecting the augmented Solow model, Bernanke and Gürkaynak (2001) nonetheless find no evidence supporting the Uzawa-Lucas model, except under implausible assumptions about the utility function. Finally, Li (2002), following Jones (1995), constructs a test of AK models based on the time-series properties of the output growth, the investment rate and the ratio of physical to human capital, obtaining mixed results. Although he finds evidence supporting a negative relationship between output growth and the physical-to-human-capital ratio - consistent with the transitional dynamics of the Uzawa-Lucas model - his results reject the hypothesis that this effect is only transitory - which is incompatible with that model.

In this paper, we test these classes of models using a complementary approach with respect to those used in these recent studies. One important difference between the one sector AK model and the UzawaLucas model is that the latter admits a well-defined transitional dynamics even in its deterministic version. Thus, in contrast with the above-mentioned papers, we can exploit the different non-linear restrictions on factor shares and speed of convergence implied by the augmented Solow and Uzawa-Lucas models to discriminate between them. To do so, we estimate a standard growth regression using Pooled Mean Group (PMG) estimators on a sample of OECD countries over the 1971-2004 period. PMG specifications allow reconciling the key assumptions of the growth models with the requirements of panel data regressions. In particular, they allow for country-specific short-term adjustments and convergence speeds, while imposing cross-country homogeneity restrictions only on the long-run coefficients. The homogeneity assumptions on the long-run coefficients is consistent with the idea that the OECD countries have access to common technologies and have intensive intra-industry trade and foreign direct investment. However, there are good reasons to assume that the speed of convergence to the steady state differ across countries (contrary to what assumed in the many studies based on standard dynamic fixed effects specifications). To anticipate the results of our analysis, we find that the speed of convergence is too fast to be compatible with the augmented Solow model, while it appears to be consistent with the Uzawa-Lucas model with constant returns to scale. In addition, the implied output elasticities are consistent with the microeconomic evidence on private returns to education.

The paper is organised as follows. Section 1 recalls the Solow model and Uzawa-Lucas models, derives an encompassing empirical specification compatible with both models and describes our strategy to discriminate between the two models on the basis of the empirical results. Section 2 discusses estimation methods, while Section 3 presents the data. The empirical results are presented in Section 4. The final section concludes. 


\section{The growth equation}

\subsection{The augmented Solow model}

We consider the human capital-augmented Solow model with a standard Cobb-Douglas production function. At time $t$ output per capita $Y$ is given by:

$$
Y(t)=K(t)^{\alpha} H(t)^{\beta}(A(t) L(t))^{1-\alpha-\beta}
$$

where $K$ and $H$ are physical and human capital respectively, $L$ is labour, $A$ captures the level of technology and $\alpha$ and $\beta$ are the partial elasticities of output with respect to physical and human capital. The time paths of the right-hand side variables are described by the following equations:

$$
\begin{aligned}
& \dot{k}=s_{k} y-(n+g+d) k \\
& \dot{h}=s_{h} y-(n+g+d) h \\
& y=k^{\alpha} h^{\beta} \\
& \dot{A}=g A \\
& \dot{L}=n L
\end{aligned}
$$

where $y=Y / A L$ and $k=K / A L$ are output and physical capital in intensive terms, $h=H / A L$ stands for average human capital, $s_{k}$ and $s_{h}$ for the investment rate in physical and human capital, $n$ is the growth rate of labour, $g$ is the rate of technological change and $d$ is the common depreciation rate. ${ }^{5}$

By taking logs, linearising around the steady state and taking into account that investment rates can be written as functions of steady state values of physical and human capital, it is a textbook exercise to show that the transitional dynamics can be expressed through the following differential equation (see e.g. Romer, 1996):

$$
\frac{d \ln y(t)}{d t}=-\lambda\left(\ln y(t)-\ln y^{*}\right)
$$

where $\lambda=(1-\alpha-\beta)(g+n+d)$ and $y^{*}$ is the steady state of output. Under the assumption that $\alpha+\beta$ $<1$ (i.e. decreasing returns to reproducible factors), output converges to its steady state and the time path of output is given by:

$$
\ln y(t)-\ln y(t-s)=\phi(\lambda)\left(\ln y(t-s)-\ln y^{*}\right)
$$

where $s$ is an arbitrary lag and $\phi(\lambda)=1-e^{-\lambda s}$. By solving [2] for $\dot{k}=0$ and $\dot{h}=0$ we can express [3] either as a function of $s_{h}$ (investment in human capital) and the other variables or as a function of $h^{*}$ (the steady-state stock of human capital) and the other variables. From an empirical point of view, the choice between the two depends on the nature of available data (Mankiw et al., 1992). In this paper human capital can be better proxied by the average years of education of the working age population and thus we are interested in the expression in terms of human capital stock:

5. To simplify the notation, the suffix $t$ has been dropped. 


$$
\ln y^{*}=\frac{\alpha}{1-\alpha} \ln s_{k}+\frac{\beta}{1-\alpha} \ln h^{*}-\frac{\alpha}{1-\alpha} \ln (n+g+d)
$$

Although $h^{*}$ is unobservable, since the system is stable, we can always approximate $\ln h^{*}$ with $\ln h(t)+\psi \Delta \ln h(t)$ with $\psi$ being a function of the parameters of the model that need not be specified. Inserting the expressions for $y^{*}$ and $h^{*}$ in equation [3] yields:

$$
\Delta \ln y(t)=-\phi(\lambda)\left(\ln y(t-s)-\frac{\alpha}{1-\alpha} \ln s_{k}-\frac{\beta}{1-\alpha} \ln h(t)-\frac{\beta \psi}{1-\alpha} \Delta \ln h(t)+\frac{\alpha}{1-\alpha} \ln (n+g+d)\right)
$$

Equation [4] can be estimated for any time interval. As we discuss in Section 3, the use of five-year or ten-year time intervals represents a loss of information, at least for the OECD sample for which annual data are available. Hence, we have retained one-year time spans in our empirical analysis. However, annual data contain short-run components that have to be accounted for. Assuming that the maximum lag is one and allowing all right-hand side variables to be time-variant, the equation can be written in the following general error correction form: ${ }^{6}$

$$
\begin{aligned}
\Delta \ln y(t)= & -\phi\left(\ln y(t-1)+\theta_{1} \ln s_{k}(t)+\theta_{2} \ln h(t)-\theta_{3} \ln (n(t)+g(t)+d(t))\right) \\
& +b_{1} \Delta \ln s_{k}(t)+b_{2} \Delta \ln h(t)+b_{3} \Delta \ln (n(t)+g(t)+d(t))+\varepsilon(t)
\end{aligned}
$$

where $\varepsilon$ is the usual i.i.d. error term. Finally, to the extent that $g$ and $d$ are not observable, we substitute $n$ for $\ln (n+g+d)$, since this term will be used only as a control. Furthermore, given that the level of technology is not observable, $\ln y$ and $\ln h$ can be proxied by GDP per capita and average years of education in the population aged 25-64, respectively, provided that a constant term and a trend are added to account for technological change. This yields:

$$
\begin{aligned}
\Delta \ln y(t)= & a_{0}-\phi\left(\ln y(t-1)+\theta_{1} \ln s_{k}(t)+\theta_{2} \ln h(t)-\theta_{3} n(t)\right)+\gamma \\
& +b_{1} \Delta \ln s_{k}(t)+b_{2} \Delta \ln h(t)+b_{3} \Delta n(t)+\varepsilon(t)
\end{aligned}
$$

To allow for a non-constant rate of technological change the same equation can also be estimated with country-specific non-linear time trend proxied by a sequence of time dummies.

\section{2}

The Uzawa-Lucas model

We will consider here the Uzawa-Lucas model with constant returns to scale. At time $t$ output in intensive terms $y=Y / A L$ is given by the following Cobb-Douglas technology:

$$
y(t)=(k(t))^{\alpha}(u(t) h(t))^{1-\alpha}
$$

where $u$ is the share of the lifetime allocated to production, while 1-u is assumed to be allocated to increase human capital. The time paths of the right-hand side variables are described by the following equations in intensive terms:

6. Higher-order lags can be easily accommodated within the same framework. 


$$
\begin{aligned}
& \dot{k}=s_{k} y-(n+g+d) k \\
& \dot{h}=B(1-u) h \\
& \dot{A}=g A \\
& \dot{L}=n L
\end{aligned}
$$

where $B$ is a constant characterising the human-capital-producing technology while, in contrast with the standard Solow model, $s_{k}$ is, for plausible values of the parameters, time-varying and determined by intertemporal preferences (see e.g. Barro and Sala-i-Martin, 1995). Furthermore, $u$ is also determined by intertemporal preferences and, in general, will not be constant.

The dynamics of the model can be represented by a three dimensional system of differential equation, with the steady-state $\tilde{y}^{*}=y^{*} / u^{*} h^{*}$ being saddle-point stable, and the system converging to it from any initial value $\tilde{y}(0)$ along a one-dimensional manifold (Mulligan and Sala-i-Martin, 1993, Caballé and Santos, 1993). Moreover, as shown by Piras (1997), along the stable manifold, the dynamics of the system can be expressed as:

$$
\frac{d \ln \tilde{y}(t)}{d t}=-\lambda\left(\ln \tilde{y}(t)-\ln \tilde{y}^{*}\right)
$$

where $\tilde{y}=y / u h$ and, in this case, $\lambda=(B+n+g+d)(1-\alpha) / \alpha$, which implies:

$$
\ln \tilde{y}(t)-\ln \tilde{y}(t-s)=\phi(\lambda)\left(\ln \tilde{y}(t-s)-\ln \tilde{y}^{*}\right)
$$

where $s$ is an arbitrary lag and $\phi(\lambda)=1-e^{-\lambda s}$. By solving [7] for $\dot{\tilde{k}}=0$, where $\tilde{k}=k / u h$ and taking logs we obtain:

$$
\ln \tilde{y}^{*}=\frac{\alpha}{1-\alpha} \ln s_{k}^{*}-\frac{\alpha}{1-\alpha} \ln \left(B\left(1-u^{*}\right)+n+g+d\right)
$$

Although $s_{k}^{*}$ is unobservable, similarly to what was done above, we can always approximate $\ln s_{k}^{*}$ with $\ln s_{k}(t)+\eta \Delta \ln s_{k}(t)$. Inserting in equation [9] the expressions for $\tilde{y}^{*}$ and $s_{k}^{*}$ yields:

$$
\Delta \ln \tilde{y}(t)=-\phi(\lambda)\left(\ln \tilde{y}(t-s)-\frac{\alpha}{1-\alpha} \ln s_{k}(t)-\frac{\eta \alpha}{1-\alpha} \Delta \ln s_{k}(t)+\frac{\alpha}{1-\alpha} \ln \left(B\left(1-u^{*}\right)+n+g+d\right)\right)
$$

Following the same steps as done above to derive equation [5] from equation [4], we can obtain the following error correction form, where $\ln \tilde{y}$ is proxied by GDP per capita divided by average years of education in the population aged $25-64:^{7}$

$$
\Delta \ln \tilde{y}(t)=a_{0}-\phi\left(\ln \tilde{y}(t-1)+\theta_{1} \ln s_{k}(t)-\theta_{3} n(t)\right)+\gamma+b_{1} \Delta \ln s_{k}(t)+b_{3} \Delta \ln n(t)+\mathcal{E}(t)
$$

7. Taking into account that $1-u$ is the share of lifetime devoted to human capital, it can be argued that average years of education of the adult population is the best possible proxy for $u h$ in the Lucas model in the same way as it is for $h$ in the augmented Solow model where $u$ can be seen as a constant (equal to 1). 
Alternatively, human capital can be switched to the right-hand side, yielding again the same expression [5]:

$$
\begin{aligned}
\Delta \ln y(t)= & a_{0}-\phi\left(\ln y(t-1)+\theta_{1} \ln s_{k}(t)+\theta_{2} \ln h(t)-\theta_{3} n(t)\right)+\varkappa \\
& +b_{1} \Delta \ln s_{k}(t)+b_{2} \Delta \ln h(t)+b_{3} \Delta n(t)+\varepsilon(t)
\end{aligned}
$$

albeit with the restriction that $\theta_{2}=1$. Again, to allow for non-constant technological change the same equation can be estimated with a non-linear country-specific time trend proxied by a sequence of time dummies.

\subsection{Discriminating between models}

The fact that equation [5] encompasses both models makes it ideal to discriminate among them. The first obvious test is to check whether the estimated value of $\theta_{2}$ is significantly different from 1 , in which case we would reject the Lucas model. However, such a test would rely very strongly on the precision with which this parameter is estimated. One might argue that the natural null hypothesis would be that the augmented Solow model is true and that a test of the hypothesis $\theta_{2}=1$ has little power.

An alternative (and far more standard) test within this framework consists of checking whether the estimated speed of convergence is compatible with its predicted value implied by the augmented Solow model given the estimated factor shares (see e.g. Mankiw et al., 1992, Caselli et al., 1996 and Bond et al. 2001). More specifically, denoting the long-run estimated coefficient of the logarithm of the investment share with $\hat{\theta}_{1}$ and that of average years of schooling with $\hat{\theta}_{2}$, the derived estimate of $\alpha$ is then equal to $\hat{\theta}_{1} /\left(1+\hat{\theta}_{1}\right)$ while that of $\beta$ to $\hat{\theta}_{2} /\left(1+\hat{\theta}_{1}\right)$. Moreover, an estimate of the speed of convergence $\lambda$ can be obtained as $-\ln (1-\hat{\phi}) / s$, where $\hat{\phi}$ is the estimated average convergence coefficient. Testing that the augmented Solow model is not rejected by the data is therefore equivalent to a test of the following nonlinear restriction:

$$
-\ln (1-\hat{\phi})=s\left(\frac{1-\hat{\theta}_{2}}{1+\hat{\theta}_{1}}\right)(n+g+d)
$$

where plausible values of the rate of technological progress $g$, the rate of growth of the population $n$, and the depreciation rate $d$ are imputed.

An alternative test for the null hypothesis that the Lucas model is valid can be developed in a similar fashion. In fact, from equation [8] we obtain:

$$
-\ln (1-\hat{\phi})=s\left(1 / \hat{\theta}_{1}\right)(B+n+g+d) .
$$

The problem with this formulation is finding a plausible estimate of the productivity of the human capital technology.Lucas (1988) calibrates $B$ to be equal to 0.05 on the basis of Denison's estimates for the US economy (Denison, 1961) and the relations implied by the model. Alternatively, we can set $u$ equal to $u=2 / 3$ - i.e. assume that individuals spend one third of their lifetime on acquiring human capital - and derive $B$ from eq. [7] as $B=(\dot{h} / h)(1 /(1-u))$. This will typically yield a much smaller value of $B$. As a further alternative, since $B>0$, we can resort to an exact one-tail test:

$$
-\ln (1-\hat{\phi})>s\left(1 / \hat{\theta}_{1}\right)(n+g+d),
$$


which can be particularly useful if the objective is to discriminate between the Solow and the Lucas model.

In practice, equations [11] and [12] imply that we can discriminate between the two models by simply glancing at the estimated parameters of equation [5], assuming that they are correctly estimated. In fact, for plausible values of the parameters, the Solow model implies a much slower speed of convergence to the steady state than that implied by the Lucas model. For instance, Taking $s=1, n=0.008$ and $(g+d)=0.05$, as typically assumed in growth empirics, if $\hat{\theta}_{1}$ and $\hat{\theta}_{2}$ are both equal to, say, $1 / 2,{ }^{8}$ with the latter not significantly different from 1 , the predicted point estimate for $\phi$ would be 0.019 , while in the Lucas model it would be at least 0.110 .

\section{The econometric approach}

The encompassing growth equation [5] can be expressed in a form that can be estimated empirically with pooled cross-country time series as follows (with, as an example, one-lag short-run dynamics):

$$
\begin{gathered}
\Delta \ln y_{i, t}=a_{0, i}-\phi_{i} \ln y_{i, t-1}+a_{1, i} \ln s_{k i, t}+a_{2, i} \ln h_{i, t}-a_{3, i} n_{i, t}+a_{4, i} t \\
+b_{1, i} \Delta \ln s_{k i, t}+b_{2, i} \Delta \ln h_{i, t}+b_{3, i} \Delta n_{i, t}+\varepsilon_{i, t}
\end{gathered}
$$

where subscripts indicate country and time ( $i$, denotes countries, $t$ time). Note that, for the time being, no cross-country restriction is imposed on the parameters.

The empirical estimation of the growth equation [13] can be performed in different ways. The choice of the econometric approach partially depends on the size of $N$ and $T$ and the quality of the data across these two dimensions. The bulk of growth regressions studies of the 1990s used cross-section data for a large number of countries (amongst the most well known contributions, see Barro and Sala-i-Martin, 1992, 1995; Mankiw et al., 1992) where the dependent variable is the average growth rate over a fairly long period (usually 20 or more years), and the explanatory variables are either long-run averages (e.g. investment shares) or variables relating to the beginning of the period (e.g. initial level of output per capita, educational enrolment, etc). The limited data requirement allows cross-section analyses to focus on large sets of countries. Moreover, the straightforward econometric procedure allows testing for different specifications and checking the robustness of coefficients to changes in the specification, e.g. using Leamer's extreme bound approach (e.g. Levine and Renelt, 1992) or the Bayesian averaging of classical estimates (BACE) approach based on averaging OLS estimates across different specifications (Sala-i-Martin, 1997, Sala-i-Martin, Doppelhofer and Miller, 2004).

Cross-section specifications offer consistent OLS estimates of the average long-run relations only under quite restrictive conditions, namely that country-specific parameters are distributed independently of the regressors and the regressors are strictly exogenous (see Pesaran and Smith, 1995). These conditions are necessarily violated in the dynamic framework of growth regressions, as in equation [13] above. In particular, the country-specific effects $\left(a_{0, i}\right)$ in the equation cannot be identified. These effects are, by construction, correlated with the lagged level of output per capita, leading to an upward bias in the estimated convergence coefficient $(-\phi)$, or equivalently, a downward bias in the estimated speed of adjustment to steady-state. Moreover, cross-section regressions ignore the possible cross-country heterogeneity of technological progress and population growth (see below).

8. In the augmented Solow model, these point estimates would imply factor shares equal to $1 / 3,1 / 3$ and $1 / 3$ for physical capital, human capital and labour, respectively. 
When studies have focused on smaller numbers of countries, such as those in the OECD area, researchers have often exploited the time dimension of the data. In order to reduce the influence of shortrun variation in the form of business-cycle effects and other processes, the most common technique has been to take averages of the data, typically 5 years (see, for example Englander and Gurney, 1994; Islam, 1995; Caselli et al., 1996, Bond et al., 2001). There are only few examples of growth regressions based on pooled cross-section and annual time-series data (e.g. Cellini, 1997, Lee et al., 1997; Crain and Lee, 1999, Bond et al., 2004).

The main advantage of panel data for the analysis of growth equations is that the country-specific effects can be controlled for, for example by using a dynamic fixed-effect (DFE) specification, which can then be estimated using standard LSDV (Least Square Dummy Variable) or GMM estimators. However, DFE specifications typically impose homogeneity of all slope coefficients, allowing only the intercepts to vary across countries. Put another way, denoting with $k$ the number of long-run parameters, DFE imposes $(N-1)(2 k+2)$ restrictions (including the short-run dynamics) on the unrestricted model in equation [13]: i.e. $k$ long-run coefficients, $k$ short-run coefficients plus the convergence coefficient and the common variance. The validity of DFE, in particular, depends critically on the assumptions of common production function and common convergence parameter, which in turn requires both common technological progress and population growth across countries (recall equations [11] and [12]). In addition, as shown by Pintus (2007) for the Solow model, income tax rates must have the same degree of progressiveness in all countries. Population growth and tax progressiveness are manifestly different across countries. Moreover, the assumption on common technological progress is difficult to reconcile with the significant differences in estimates of multifactor productivity growth across countries (see e.g. Bassanini and Scarpetta, 2002a). Finally, the assumption of cross-country homogeneity of the rate of convergence appears to be at odds with data for OECD countries (Bassanini and Scarpetta, 2002b). Pesaran and Smith (1995) show that, under slope heterogeneity, both LSDV and GMM DFE estimates of the speed of convergence are usually affected by a downward heterogeneity bias. ${ }^{9}$ Consequently, DFE estimators do not appear suitable to implement our test.

An alternative strategy is the mean-group approach (MG), which consists of estimating separate regressions for each country and calculating averages of the country-specific coefficients (e.g. Evans, 1997; Lee et al., 1997). In particular, in specifications with one lag for all observables except the trend, there are $N(2 k+3)$ parameters to be estimated: each equation has $2 k$ coefficients on the exogenous regressors, an intercept, a coefficient on the lagged dependent variable and a variance. Albeit consistent, this estimator is likely to be inefficient in small country samples, where any country outlier could severely influence the averages of the country coefficients.

Following (Pesaran et al., 1999), we take an intermediate route between imposing homogeneity on all slope coefficients (DFE) and imposing no restrictions (MG), by using the pooled mean group approach (PMG). This approach consists in allowing short-run coefficients, the speed of adjustment and error variances to differ across countries, but imposing homogeneity on long-run coefficients. In other words, we impose $(N-1) k$ non-linear restrictions on the unrestricted model shown in equation [13], and estimate:

9. Instrumental variable GMM estimators are particularly suited to deal with endogeneity problems in dynamic panel data, and are therefore generally applied to overcome the downward dependent variable bias that would emerge with LSDV estimators when $N$ is large and $T$ relatively small. As shown by Nickell (1981), however, the downward lagged dependent variable bias is a declining function of T (i.e. it depends on $1 / T$ ) and thus it is less of a concern when $T$ is large and of the same order of magnitude of $N$. Indeed, as shown by Judson and Owen (1999), the LSDV estimator usually performs as well as GMM estimators for $T=30$. In this latter case, the heterogeneity of individuals (countries) is a more serious problem, and imposing homogeneity of all (short and long-run) parameters risk leading to inconsistent results (see Pesaran and Smith, 1995, Lee et al., 1997). 


$$
\begin{gathered}
\Delta \ln y_{i, t}=-\phi_{i}\left(\ln y_{i, t-1}-\theta_{1} \ln s_{k i, t}-\theta_{2} \ln h_{i, t}+\theta_{3} n_{i, t}-a_{4, i} t-\theta_{0, i}\right) \\
+b_{1, i} \Delta \ln s_{k i, t}+b_{2, i} \Delta \ln h_{i, t}+b_{3, i} \Delta n_{i, t}+\varepsilon_{i, t}
\end{gathered}
$$

where the non-linear restrictions are $a_{k, i} / \phi_{i}=\theta_{k}$. The maximum likelihood estimator of eq. [14] is usually called PMG estimator. Although, as discussed above, it is difficult to assume homogeneity of speed of convergence and short-term dynamics as in DFE specifications, the assumption of common long-run production function parameters appears more reasonable for OECD countries, given their easy access to common technologies, and the intense trade relations. Under long-run slope homogeneity the PMG estimator increases the efficiency of the estimates with respect to MG estimators (Pesaran et al., 1999).

The hypothesis of homogeneity of long-run parameters cannot be assumed a priori and we test it empirically in all specifications. In particular, we use a Hausman test (Hausman, 1978) for this purpose: under the null hypothesis, the difference in the estimated coefficients between unrestricted $\mathrm{MG}$ and restricted PMG specifications is not significantly different from zero and estimates obtained using the restricted (PMG) specifications are more efficient.

\section{The data}

We estimate the growth equation on data for 21 OECD countries over the period 1971-2004. ${ }^{10}$ The variables we use are as follows (basic descriptive statistics of these variables are shown in Table 1):

- Dependent variable $(\Delta \log y)$. Growth in real GDP per head of population aged 15-64 years, expressed in 2000 purchasing power parities (PPP).

- Convergence variable $\left(\log y_{-1}\right)$. Lagged logarithm of real GDP per head of population aged 15-64 years, in 2000 PPPs.

- Physical capital accumulation $\left(\log S_{k}\right)$. The propensity to accumulate physical capital is proxied by the logarithm of ratio of real non-residential fixed capital formation to real GDP.

- Stock of human capital $(\log h)$ is proxied by the logarithm of the average number of years of schooling of the population aged between 25 and 64 years. ${ }^{11}$

- Population growth $(\Delta \log n)$. Growth in the working age population (15-64 years) in percentage points.

Growth regressions have been estimated in the literature using either GDP per person employed or, more frequently, GDP per capita (generally referring to working age population to avoid problems related to differences in the demographic structure). Under the assumption of full employment and stable participation rates, these two specifications yield the same results and the choice depends on the availability and quality of data on population and employment. However, employment rates (employment over population of working age) have changed significantly over time in most OECD countries, and particularly so in Continental Europe where significant declines were recorded in the 1980s and 1990s and

10. The country sample include: Australia, Austria, Belgium, Canada, Denmark, Finland, France, Germany (western Germany, up to 1989 only), Greece, Ireland, Italy, Japan, Netherlands, New Zealand, Norway, Portugal, Spain, Sweden, Switzerland, United Kingdom and United States.

11. See table 6 for the data. One of the main sources of variation of this variable is through graduation of students enrolled in tertiary education. As they are unlikely to have been employed for the entire year of graduation, we prefer to lag this variable one year. 
some recovery has been observed in recent years. The resulting path of GDP per worker is strongly affected by short- and long-run fluctuations in the employment rate, due to composition effects (see e.g. OECD, 2007). Under these conditions, a specification in GDP per person employed is likely to yield different results from that in GDP per capita and to be less informative of both convergence and the role of investment in physical and human capital.

Various measures of human capital have been used in growth regressions. Given the objective of this paper - estimating equation [5] in order to discriminate between the Uzawa-Lucas and augmented Solow models - we use a measure of average years of education in working-age population to proxy the human capital stock, which is a natural choice for the Lucas model. Nevertheless, even in the standard augmented Solow framework, there are practical and theoretical reasons that suggest the use of a stock variable for human capital. First, data on enrolment rates are generally of lower quality than years of education, and changes in enrolment are likely to affect growth only with long lags, which are difficult to accommodate in our framework. Second, the alternative of using changes in years of education as a proxy for the accumulation of human capital is not suitable, as it refers to a net investment in human capital rather than the required measure of gross investment. Finally, reverse causality problems are less severe when a stock measure is considered (see, e.g., Temple, 2000).

The data used in this paper are from the following sources: ${ }^{12}$

- Data on GDP, working age population, and gross fixed capital formation are from the OECD Annual National Accounts (ANA). Purchasing Power Parity benchmarks for 2000 are from the OECD Statistics Department. Western Germany is only included up to 1989.

- Data on the average years of education of the working age population have been obtained by updating the OECD dataset on average years of education (see Bassanini and Scarpetta, 2002b) with recent information from the OECD Education at a Glance (see Annex Table A.1). ${ }^{13}$ Average years of educational attainment are estimated on the basis of completed levels of education and average years of schooling at each level of education amongst the population of working age.

Table 1. Basic Statistics

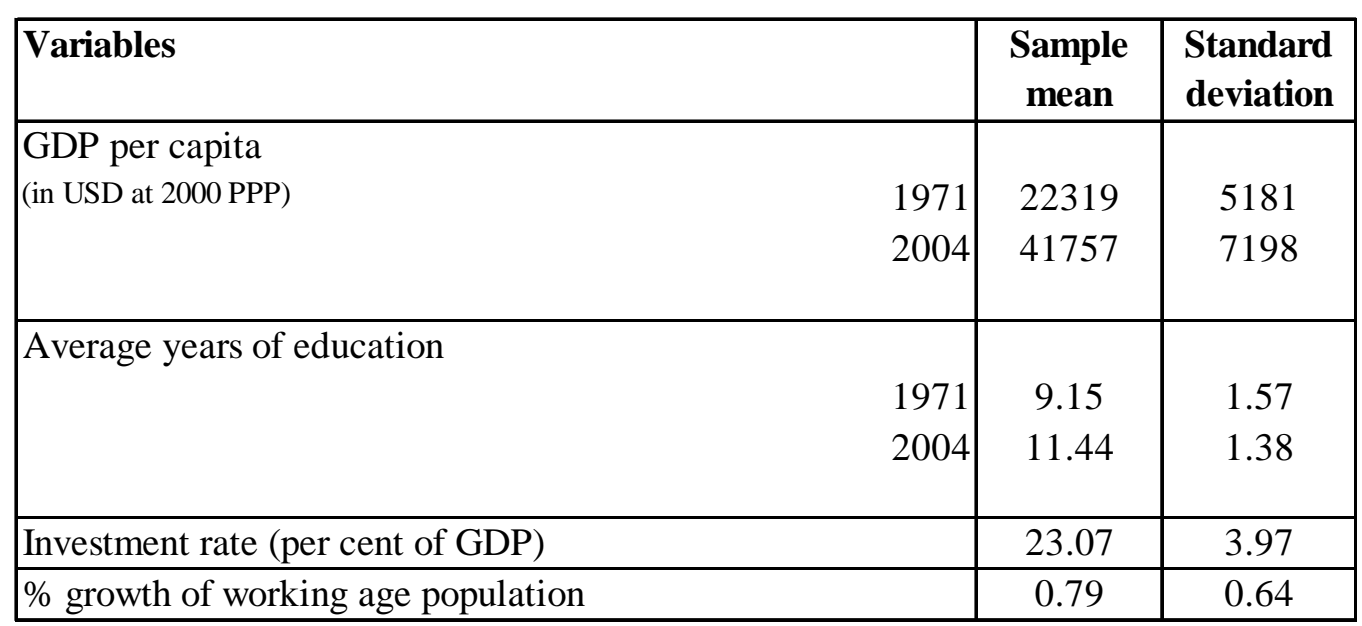

12. The full dataset used for this paper can be downloaded at http://bassax.freeyellow.com/Solowlucasdata.zip.

13. The original dataset drew from a version of the Barro and Lee data set revised by de la Fuente and Doménech (2006) and OECD data. 


\section{Empirical results}

\subsection{Model selection and sensitivity analysis}

As discussed above, we estimate equation [5] using a Pooled Mean Group (PMG) estimator following Pesaran et al. (1999), and check that the assumption of slope homogeneity for the long run parameters is not rejected. A crucial question for estimating equation [5] is how to control for time influences in the growth regressions. Table 2 reports our estimation results using different ways to treat time influences. In the first column, a benchmark model is estimated without any time controls. In the second column, country-specific linear time trends are included. This should be sufficient to control for influences related to time as long as time-effects on the OECD growth path evolved linearly. In comparison with estimates from the model with no controls for time effects, the model with time controls implies noticeably faster estimates of the speed of convergence.

However, the likelihood that non-linear trends affect the data is a priori relatively high. One standard way to test the robustness of results in the presence of a possible non-linear time trend relies on the introduction of (common) time dummies. The inclusion of cross-country homogeneous time dummies instead of heterogeneous time trends, however, implies that all countries in the sample are affected by common shocks, which is quite a strong assumption, particularly in a framework where the speed of convergence and short-run parameters are assumed to be heterogeneous. When dummies are defined for a set of years, however, it is possible to estimate equations wherein period dummies are country-specific without running out of degrees of freedom. In the third column of Table 2, we include country-specific dummies for consecutive 5-year periods.

As mentioned above, the validity of our choice of estimator hinges on whether homogeneous slopes can be imposed for the estimated long-run parameters. With the exception of the model without any time controls, the homogeneity restriction on the long run coefficients is not rejected by the Hausman tests, as reported in the bottom row of Table 2. This gives us confidence that the Pooled Mean Group estimator is indeed an appropriate choice for our data. The coefficients on both physical and human capital are highly significant. Overall, the estimated partial elasticity of output with respect to physical capital is relatively low, while that of human capital is relatively high, although still in line with the microeconomic literature on private returns from schooling. Using an (average) estimate of the private returns to one additional year of schooling of about $8 \%$ and a labour share of 0.6, Topel (1999) suggested an upper bound value for the impact of schooling on output per capita of about 13\%. Similarly, our estimated long-run elasticity of output per capita to human capital implies that one additional year of schooling raises output per capita by $6-9 \%$. 
Table 2. PMG Estimation Results

Dependent variable: Growth of Log GDP per capita

\begin{tabular}{|c|c|c|c|c|c|c|}
\hline \multirow{2}{*}{$\begin{array}{l}\text { Model } \\
\text { Long-Run Parameters }\end{array}$} & \multicolumn{2}{|c|}{$\begin{array}{c}(1) \\
\text { No time } \\
\text { controls }\end{array}$} & \multicolumn{2}{|c|}{$\begin{array}{l}\text { (2) } \\
\text { Linear time } \\
\text { trend }\end{array}$} & \multicolumn{2}{|c|}{$\begin{array}{c}\text { (3) } \\
\text { 5-year } \\
\text { dummies }\end{array}$} \\
\hline & & & & & & \\
\hline Log investment rate & $\begin{array}{c}0.63 \\
(0.12)\end{array}$ & $* * *$ & $\begin{array}{c}0.29 \\
(0.03)\end{array}$ & *** & $\begin{array}{c}0.15 \\
(0.04)\end{array}$ & *** \\
\hline Population Growth & $\begin{array}{l}-0.23 \\
(0.04)\end{array}$ & $* * *$ & $\begin{array}{l}-0.05 \\
(0.01)\end{array}$ & *** & $\begin{array}{l}-0.05 \\
(0.01)\end{array}$ & *** \\
\hline Human Capital & $\begin{array}{c}1.10 \\
(0.13)\end{array}$ & *** & $\begin{array}{c}0.74 \\
(0.16)\end{array}$ & *** & $\begin{array}{c}0.95 \\
(0.12)\end{array}$ & *** \\
\hline \multicolumn{7}{|l|}{ Short Run Parameters } \\
\hline Average convergence parameter & $\begin{array}{l}-0.07 \\
(0.01)\end{array}$ & $* * *$ & $\begin{array}{l}-0.22 \\
(0.03)\end{array}$ & *** & $\begin{array}{l}-0.27 \\
(0.03)\end{array}$ & *** \\
\hline Estimated Returns to Scale for Reproducible Factors & 1.060 & & 0.800 & & 0.960 & \\
\hline Test for Constant Returns to Scale & 0.433 & & 0.113 & & 0.657 & \\
\hline Hausman Test of Long-Run Slope Homogeneity (P-value) & 0.085 & * & 0.564 & & 0.577 & \\
\hline Observations & 699 & & 699 & & 699 & \\
\hline
\end{tabular}

Short-run parameters are not presented (except for the convergence parameter). Standard errors in parentheses. ***, *: significant at the $1 \%$ and $10 \%$ level, respectively.

\subsection{Consistency with different theoretical models}

Two additional striking features emerge by looking at Table 2. First, the null hypothesis of constant returns to physical and human capital is never rejected by the data. Hence, our first rough test cannot reject the hypothesis that the Uzawa-Lucas model with constant returns to scale provides a better representation of the data. Yet, the width of the confidence intervals tends to suggest that this test has a very low power. ${ }^{14}$ Second, we estimate a very high convergence parameter, which is clearly inconsistent with the augmented Solow model. More precisely, the first three rows of Table 3 reports output elasticities and average values for $\lambda$ as derived from the estimated equations. The next two lines report "predicted" theoretical values of $\lambda$ that would be compatible with the derived output elasticities on the basis of growth specification (2) and (3) in Table 2. In other words, they report the the speed of convergence predicted by the right-hand side of eq. [11] in the case of the Solow model and of eq. [12] in the case of the Lucas model. As standard, in the case of the Solow model, predicted values are computed on the basis of plausible values for the population growth rate, the depreciation rate and the rate of technological progress. For population growth, we take the average value across our sample $(0.8 \%)$. For the depreciation rate, we assume a standard value of $2 \%$. For technological progress, we consider the average estimated time trend (1.26\%) or the average annual shift implied by the estimated 5-year dummies $(0.92 \%)$, depending on the specification. For these values,

14. Indeed, as indicated in section 1, in the Uzawa-Lucas model we would expect the coefficient of human capital to be equal to one under constant returns to scale. If we take the model with a linear trend, the confidence interval at the 5\% level on the human capital coefficient ranges between 0.47 and 1.02. Conversely if we take the model with country-specific time dummies, the corresponding confidence interval ranges between 0.71 and 1.18. 
the point-estimates of $\lambda$ are more than twenty times greater than what the Solow model would imply given the estimates of the other parameters. ${ }^{15}$

In the case of the Lucas model, we need to impute also a value for the slope parameter of the human capital production function $(B)$. From equation [7] above, we can write $B=(\dot{h} / h)(1 /(1-u))$. Assuming that individuals spend one third of their lifetime on acquiring human capital, i.e. $u=2 / 3$, and using the observed average growth rate of human capital in the sample $(0.79 \%)$, we obtain a value of $B$ equal to 0.0236. Alternatively we can use Lucas' calibration at 0.05 (Lucas, 1988). Using equation [12] and these two proxies for $B$, we obtain theoretical speeds of convergence that are close or above our estimated values.

As a next step, we perform a Wald test for the consistency of our estimated parameters within the Solow and Uzawa-Lucas models. This implies testing that the non-linear hypotheses implied by eq. [11] and [12], respectively, are not rejected by the data at standard statistical levels. The last rows of Table 3 show the Wald test statistics and P-values, computed assuming the same values as above for unobservables and using the average estimated value of $\lambda$. Not surprisingly, it appears that the Solow model is always rejected by the data at conventional statistical levels. By contrast, the Uzawa-Lucas model is never rejected. From the statistics reported in Table 3, it is also immediately evident that the one-tail test corresponding to eq. [12a] can never reject the Uzawa-Luca model.

Table 3. Derived parameters and speed of convergence tests

\begin{tabular}{|c|c|c|c|}
\hline derived parameters & & Trend & Dummies \\
\hline$\alpha^{1}$ & & 0.22 & 0.13 \\
\hline$\beta^{2}$ & & 0.58 & 0.82 \\
\hline average $\lambda^{3}$ & & 0.246 & 0.310 \\
\hline Solow: theoretical $\lambda$ & & 0.008 & 0.002 \\
\hline Lucas: theoretical $\lambda, u=2 / 3$ & & 0.223 & 0.403 \\
\hline Lucas: theoretical $\lambda, B=0.05$ & & 0.315 & 0.577 \\
\hline \multirow[t]{2}{*}{ Speed of convergence test: Solow model (Eq 11): } & $\chi^{2}(1)$ & 38.93 & 48.55 \\
\hline & p-value & 0.00 & 0.00 \\
\hline \multirow[t]{2}{*}{ Speed of convergence test: Lucas model (Eq 12, $u=2 / 3)$ : } & $\chi^{2}(1)$ & 0.28 & 0.56 \\
\hline & p-value & 0.60 & 0.46 \\
\hline \multirow[t]{2}{*}{ Speed of convergence test: Lucas model (Eq 12, B=0.05): } & $\chi^{2}(1)$ & 2.15 & 2.41 \\
\hline & p-value & 0.14 & 0.12 \\
\hline
\end{tabular}

Trend and Dummies, refer to specifications in Table 2. Imputed parameters: population growth: 0.008; depreciation rate: 0.02 ; technological change: 0.0126 in the Trend model and 0.0092 in the Dummies model; and $B: 0.0236$.

1. Estimated partial elasticity to physical capital.

2. Estimated partial elasticity to human capital.

3. Estimated average speed of convergence.

15. Even if we set the depreciation rate to a much higher value (say 10\%, as estimated by Jorgenson and Stiroh, 2000, for certain capital goods), and allow technological progress to growth at a higher 3\%, our estimated speed of convergence is far too high to be compatible with the augmented Solow model. 


\section{$\mathrm{ECO} / \mathrm{WKP}(2007) 52$}

We checked the sensitivity of our results to country coverage by excluding countries one-by-one and re-estimating specifications on the restricted sample. We then perform again Wald tests on the speed of convergence, using the same imputed parameters as above: in all restricted sample the corresponding test statistics appear inconsistent with the Solow model while in no sample is the Uzawa-Lucas model rejected. ${ }^{16}$ Given these results, it seems reasonable to conclude that according to our estimates, the growth experience of OECD countries is not inconsistent with the Lucas model with constant returns to scale.

\subsection{Further sensitivity analysis}

As in any panel regression on macro data, attention should be paid to possible endogeneity problems: in our growth regression, in particular, both the accumulation of human and physical capital can be endogenous. We address these two possible endogeneity issues in turn in this section.

\section{Estimating the constrained equation}

As discussed in the previous section, the use of stock data for human capital in equation [14] mitigates the reverse causality problem, but it does not settle the issue completely. In the Lucas model with constant returns to scale, the coefficient of human capital is exactly equal to 1, a hypothesis that we cannot reject on the basis of our estimates presented in Table 2. These theoretical and empirical considerations suggest that we may simply restrict the coefficient on human capital to be one, in order to gain efficiency on the remaining parameter estimates and perform our test on the speed of convergence without any risk of a bias from the possible endogeneity of human capital. Following equation [10] and our discussion in the previous section, imposing the unitary coefficient on human capital implies rewriting the dependent variable in the growth equation as the logarithm of GDP per capita divided by average years of education. In other words, the constrained version of eq. [14] reads as:

$$
\begin{gathered}
\Delta \ln \tilde{y}_{i, t}=-\phi_{i}\left(\ln \tilde{y}_{i, t-1}-\theta_{1} \ln s_{k i, t}+\theta_{3}\left(n_{i, t}+\Delta \ln h_{i, t}\right)-a_{4, i} t-\theta_{0, i}\right) \\
+b_{1, i} \Delta \ln s_{k i, t}+b_{3, i}\left(\Delta n_{i, t}+\Delta \ln h_{i, t}\right)+\varepsilon_{i, t}
\end{gathered}
$$

Estimates from equation [15], are presented in Table 4. Two-tail speed of convergence tests are reported at the bottom of the table. It appears that the Lucas model with constant returns to scale cannot be rejected by the data at conventional statistical level, subject to the same choice of imputed parameters as above. $^{17}$

16. The results of these sensitivity tests are available from the authors on request.

17. One-tail tests (not reported) are also supportive of this statement. 
Table 4. PMG Estimation Results of the constrained equation

Dependent variable: Growth of Log GDP divided by total years of education

\begin{tabular}{|c|c|c|c|c|}
\hline \multirow{2}{*}{$\begin{array}{l}\text { Model } \\
\text { Long-Run Parameters }\end{array}$} & \multicolumn{2}{|c|}{$\begin{array}{l}\text { (1) } \\
\text { Linear time } \\
\text { trend }\end{array}$} & \multicolumn{2}{|c|}{$\begin{array}{c}\text { (2) } \\
\text { 5-year } \\
\text { dummies }\end{array}$} \\
\hline & & & & \\
\hline Log investment rate & $\begin{array}{c}0.28 \\
(0.02)\end{array}$ & & $\begin{array}{c}0.16 \\
(0.04)\end{array}$ & \\
\hline Growth of total years of education & $\begin{array}{l}-0.05 \\
(0.01)\end{array}$ & *** & $\begin{array}{l}-0.05 \\
(0.01)\end{array}$ & *** \\
\hline \multicolumn{5}{|l|}{ Short Run Parameters } \\
\hline Average convergence parameter & $\begin{array}{l}-0.22 \\
(0.03)\end{array}$ & *** & $\begin{array}{l}-0.27 \\
(0.03)\end{array}$ & *** \\
\hline Hausman Test of Long-Run Slope Homogeneity (P-value) & 0.56 & & 0.46 & \\
\hline Average estimated $\lambda$ & 0.24 & & 0.31 & \\
\hline Theoretical $\lambda(\operatorname{Eq~12,~} u=2 / 3)$ & 0.23 & & 0.39 & \\
\hline Speed of convergence test: Lucas model (Eq 12, $u=2 / 3): \chi^{2}(1)$ & 0.14 & & 0.51 & \\
\hline P-value & 0.71 & & 0.48 & \\
\hline Theoretical $\lambda(\operatorname{Eq~12,~} B=0.05)$ & 0.32 & & 0.56 & \\
\hline Speed of convergence test: Lucas model (Eq 12, $B=0.05): \chi^{2}(1)$ & 3.26 & * & 2.65 & \\
\hline P-value & 0.07 & & 0.10 & \\
\hline Observations & 678 & & 678 & \\
\hline
\end{tabular}

Short-run parameters are not presented (except for the convergence parameter). Standard errors are reported in parentheses. ${ }^{* *}$, ${ }^{*}$ : significant at the $1 \%$ and $10 \%$ level, respectively.

\section{Mean Group GMM estimates of the constrained equation}

As a second robustness check, we address the possible endogeneity of the investment rate in equations [14] and [15], which would cast doubt on our tests for the speed of convergence. The problem is complicated by the fact that it is difficult to find a proper instrument for investment, i.e an exogenous variable affecting the investment rate without directly affecting, or being affected by, GDP per capita growth (see e.g. Sianesi and van Reenen, 2003). One way to sort out this problem is to exploit the lag structure of the different variables by implementing a GMM estimator. This is relatively cumbersome in a model in which long-run parameters are restricted to be common across countries while the convergence parameters are not, since it involves estimating a GMM model with additional non-linear restrictions. Conversely, as suggested by Bond, Leblebicioglu and Schiantarelli (2004), this is relatively straightforward in an un-restricted model where both short and long-run parameters are assumed to be heterogeneous (that is a MG specification). Given that our interest lies on the common (or averaged) long-run parameters, we can obtain consistent - albeit relatively inefficient - estimates of their values by taking averages of estimated parameters. As the GMM estimation is sensitive to the number of parameters to be estimated, and this problem can be particularly important in our MG version of the GMM estimator, we estimate with this method only the constrained model with country-specific trends. Table 5 presents difference GMMMG estimates for two alternative specifications of this model: in column 1, the short-run dynamics for all variables is included; while in column 2 the short-run dynamics of the growth of population and human capital is omitted to further reduce the number of parameters. 
Results from this exercise appear to confirm that the Uzawa-Lucas model with constant returns to scale provides an appropriate representation of the data. First, in both specifications, the estimated speed of convergence is above the theoretical speed of convergence that can be derived from partial output elasticities. Hence, trivially, one-tail tests cannot reject the model. Second, at conventional statistical levels, under the standard assumptions for imputed parameters, two-tail tests cannot reject the model as well. Overall, taking into account the uncertainty about the productivity parameter in the human capital production function, it appears that the evidence provided in this exercise is reasonably consistent with the Lucas model.

Table 5. Difference GMM-MG Estimation Results of the constrained equation

Dependent variable: Growth of Log GDP divided by total years of education

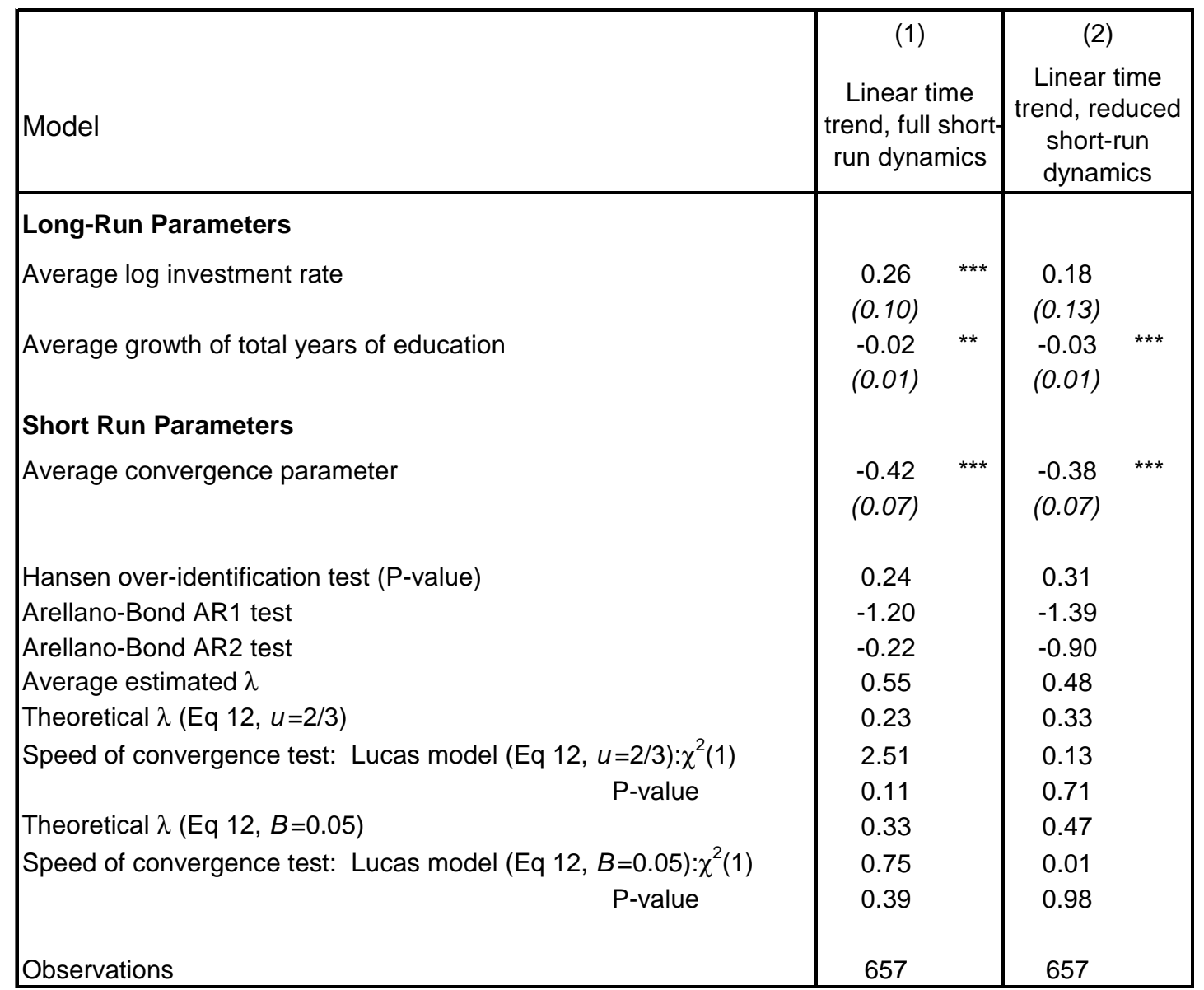

Short-run parameters are not presented (except for the convergence parameter). Heteroskedasticity-consistent standard errors are reported in parentheses. The average growth of total years of education (population growth plus growth of average years of education) is treated as exogenous. Beyond exogenous variables, instruments include the second and third lag of the level of logGDP divided by total years of education and the second and third lag of the level of the log investment rate. No short-run dynamics for the growth of total years of education is included in the second column. ${ }^{* * *},{ }^{* *}$ and ${ }^{*}$ : significant at the $1 \%, 5 \%$ and $10 \%$ level, respectively. 


\section{Concluding remarks}

This paper provides empirical evidence on the role of human capital accumulation for economic growth in a sample of 21 OECD countries over the 1971-2004 period. Our main objective is to assess whether the data are more consistent with the human-capital augmented Solow model of exogenous growth, or with an endogenous growth model à la Uzawa-Lucas with constant returns to scale to "broad" (human and physical) capital. This distinction has important implications for our understanding of the process of economic growth and the role of policies in influencing it. In the world of Solow, human capital enhancing policies would have a temporary effect on economic growth during the transition towards the new steady-state growth path of output, while in the Uzawa-Lucas model the growth effect would be more persistent.

Discriminating between these two models requires, first of all, good quality data for a sufficiently long time period. We use a proxy for human capital based on the average number of years of formal education of the working age population, drawing on updated OECD data. Moreover, in line with the requirements of the growth model, we apply an econometric technique, the pooled mean group estimator (PMG), which allows for speed of convergence, short-term dynamics and variances to vary across countries. This makes our approach different from most panel-data approaches that impose homogeneity restrictions on all these parameters. Consistent with a few recent studies (e.g. Bassanini and Scarpetta, 2002b, De La Fuente and Domenech, 2006, Cohen and Soto, 2007), our results point to a positive and significant impact of human capital accumulation to output per capita growth. The estimated long-run effect on output of one additional year of education (about 6-9\%) is also within the range of the estimates obtained in microeconomic analyses of the private returns to schooling. Our results also suggest a significant growth effect from the accumulation of physical capital and a rapid speed of convergence to the steady state growth path of output.

We exploit the different non-linear restrictions on factor elasticities and speed of convergence implied by the augmented Solow and Uzawa-Lucas models to discriminate between them. Our estimated speed of convergence appears to be too high to be consistent with the human-capital-augmented version of the Solow model, but rather support the endogenous growth model à la Uzawa-Lucas. This main finding is robust to several robustness tests. In particular, we find that our results are unaffected by the exclusion of any of the countries in our sample. Moreover, we tackle the potential endogeneity problems of both human and physical capital in the growth model by using a restricted version of the growth equation and instrumental variables, and again find results that cannot reject the Uzawa-Lucas model. All in all, it seem reasonable to conclude that, according to our results, the growth experience of the OECD countries over the past three decades is more consistent with an endogenous process in which the accumulation of human capital can have a persistent effect on growth. Further work is needed to corroborate this conclusion, in particular to improve our proxies of human capital. While this paper uses a harmonized series, more needs to be done to account for changes in the quality of education and in the skill composition and not just in the number of years of schooling. 
இ)

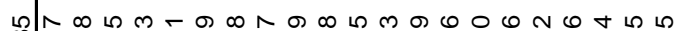

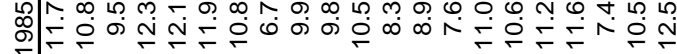

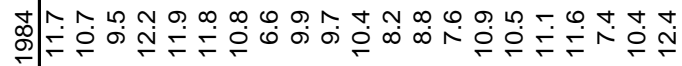

m

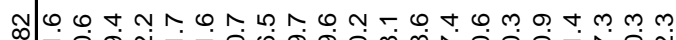

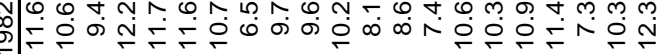

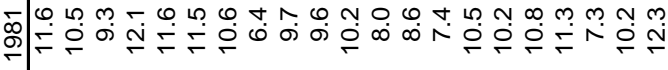

ષั

ผें

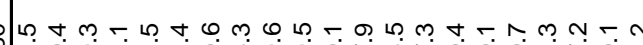

ปั

ฮั

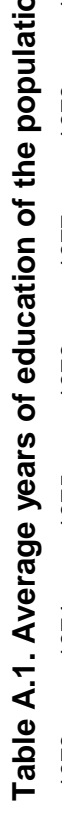

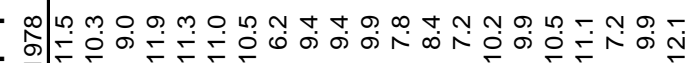

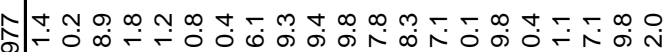

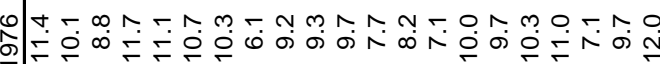

n

要

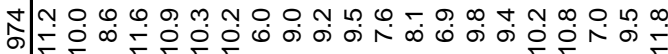

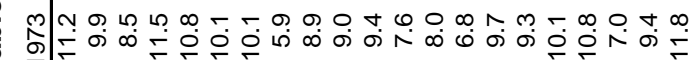

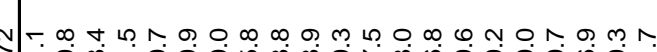

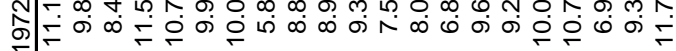

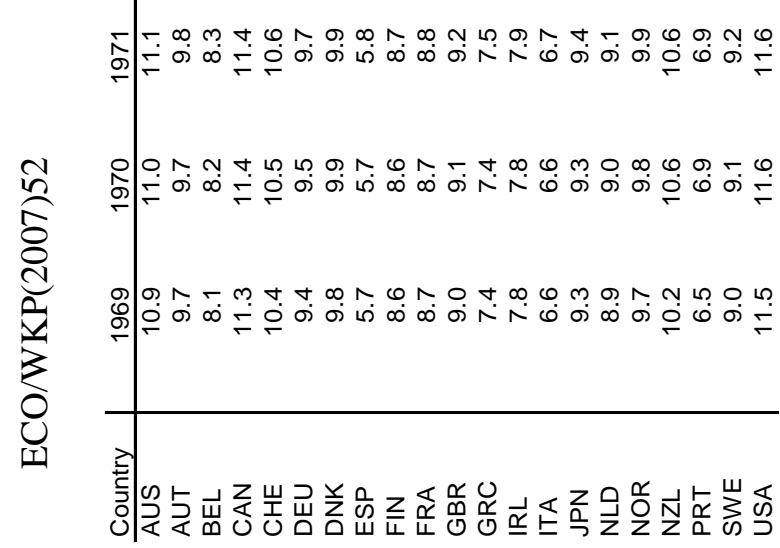

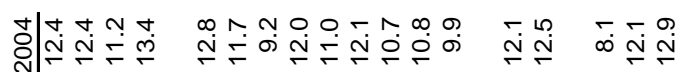

$m \infty-\forall-\infty \omega 000-m \infty \infty \forall \sigma \forall \infty \infty-\sigma$

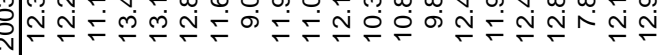

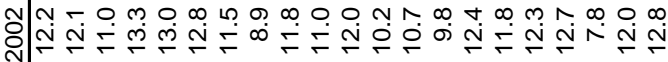

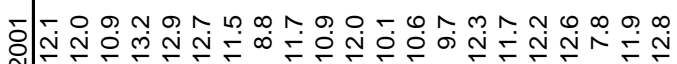

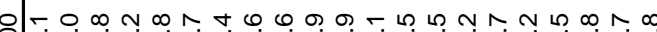

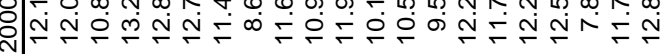

/

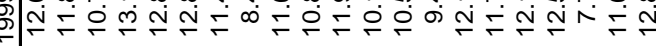

m

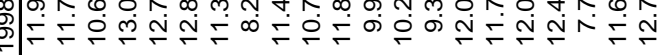

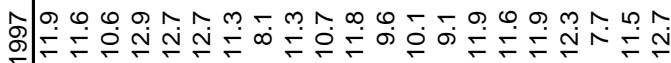

\&

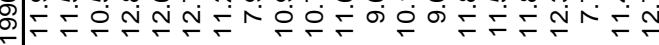

นด

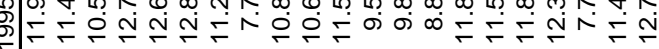

मे ปิ

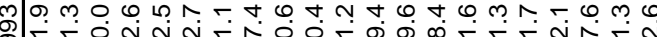

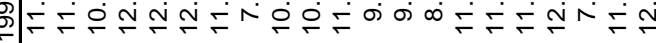

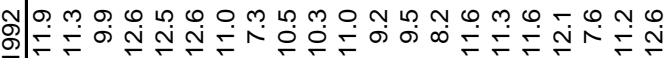

-

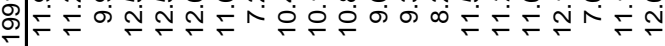

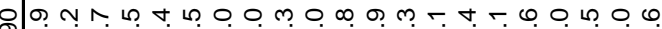

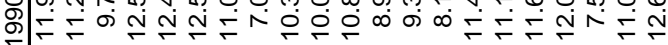

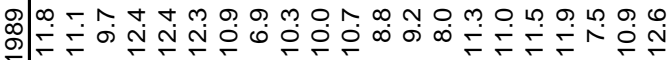

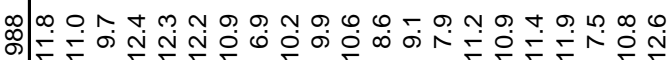




\section{Bibliography}

BARRO, R.J. and X. SALA-I-MARTIN (1992), “Convergence”, Journal of Political Economy, 100, pp. 223-251.

BARRO, R.J. and X. SALA-I-MARTIN (1995), Economic Growth, New York, McGraw-Hill.

BASSANINI, A. and S. SCARPETTA (2002a), "Growth, Technological Change and ICT Diffusion: Recent evidence from OECD countries", Oxford Review of Economic Policy, 18, 324-344.

BASSANINI, A. and S. SCARPETTA (2002b), "Does Human Capital Matter for Growth in OECD Countries? A Pooled Mean Group Approach”, Economics Letters, 74(3), 399-405.

BERNANKE, B. and R. GURKAYNAK (2001), "Is Growth Exogenous? Taking Mankiw, Romer, and Weil Seriously", NBER Working Paper: 8365.

BOND, S., A. HOEFFLER and J. TEMPLE (2001), "GMM Estimation of Empirical Growth Models", CEPR Discussion Paper: 3048.

BOND, S., A. LEBLEBICIOGLU and F. SCHIANTARELLI (2004), "Capital Accumulation and Growth: A New Look at the empirical Evidence, IZA Discussion Paper, 1174.

CABALLÉ, J. and M. SANTOS (1993), “On Endogenous Growth with Physical and Human Capital”, Journal of Political Economy, 101, pp. 1042-1067.

CARD, D. (1999), "The causal effects of schooling on earnings", in O. Ashenfelter and D. Card (eds.) "Handbook of Labor Economics", Amsterdam, North Holland.

CASELLI, F., G. ESQUIVEL and L. FERNANDO (1996), "Reopening the convergence debate: a new look at cross-country growth empirics", Journal of Economic Growth, 1, 363-389.

COHEN, D. and M. SOTO (2007), "Growth and Human Capital: Good Data, Good Results”, Journal of Economic Growth, 12, pp. 51-76.

CRAIN, W.M. and K.J. LEE (1999), "Economic growth regressions for the American states: A sensitivity analysis", Economic Inquiry, 37, pp. 242-257.

DE LA FUENTE, A. and R. DOMÉNECH (2006), "Human capital in growth regressions: How much difference does data quality make?" Journal of the European Economic Association, 4(1), 1-36.

DE LA FUENTE, A. and R. DOMÉNECH (2001), "Schooling Data, Technological Diffusion, and the Neoclassical Model”, American Economic Review Papers \& Proceedings, 91, 323-327.

DENISON, E.F. (1961), The Sources of Economic Growth in the United States, CED, New York.

ENGLANDER, S. and A. GURNEY (1994), "Medium-term determinants of OECD productivity", OECD Economic Studies, No. 22, spring.

EVANS, P. (1997), "How fast do economies converge", The Review of Economics and Statistics, 79(2), pp. 219-25.

HAUSMAN, J. (1978), "Specification tests in econometrics", Econometrica, 46, pp. 1251-1271. 
ISLAM, N. (1995), “Growth Empirics: A Panel Data Approach”, Quarterly Journal of Economics, 110, 1127-1170.

JONES, C.I. (1993), "Time Series Tests of Endogenous Growth Models”, Quarterly Journal of Economics, $110,495-525$.

JORGENSON, D.W. and K.J. STIROH (2000), "Raising the Speed Limit: U.S. Economic Growth in the Information Age", Brookings Papers on Economic Activity, August.

JORGENSON, D.W., F.M. GOLLOP and B.M. FRAUMENI (1987), "Productivity and U.S. economic growth", Cambridge, MA. Harvard Univ. Press.

JUDSON, R.A. and A.L. OWEN (1999), "Estimating Dynamic Panel Data Models: A Guide for Macroeconomists", Economics Letters, 65, 9-15.

KRUEGER, A.B. and M. LINDAHL (2001), "Education and Growth: Why and for whom?", Journal of Economic Literature.

LEE, K., M.H. PESARAN and R. SMITH (1997), "Growth and convergence in a multi-country empirical stochastic Solow model”, Journal of Applied Econometrics, 12, pp. 357-392.

LEVINE, R. and D. RENELT (1992), "A sensitivity analysis of cross-country growth regressions", American Economic Review, 82 (4), pp. 942-963.

LI, D. (2002), "Is the AK Model Still Alive? The Long-Run Relation between Growth and Investment Reexamined", Canadian Journal of Economics, 35, 92-114.

LUCAS, R.E. (1988), "On the mechanics of economic development”, Journal of Monetary Economics, 22.

MANKIW, G.N., D. ROMER and D.N. WEIL (1992), "A contribution to the empirics of economic growth”, Quarterly Journal of Economics, 107, pp. 407-37, May.

MULLIGAN, C.B. and X. SALA-I-MARTIN (1993), "Transitional Dynamics in Two-Sector Models of Endogenous Growth”, Quarterly Journal of Economics, 108, pp. 739-773.

NICKELL, S. (1981), "Biases in dynamic models with fixed effects", Econometrica, 49, pp. 1399-1413.

OECD (2007), Employment Outlook, Paris.

PESARAN, M.H. and R. SMITH (1995), "Estimating long-run relationships from dynamic heterogeneous panels", Journal of Econometrics, 68, (1), pp. 79-113.

PESARAN, M.H., Y. SHIN and R. SMITH (1999), "Pooled Mean Group estimation of dynamic heterogeneous panels", Journal of the American Statistical Association, 94, pp. 621-634.

PINTUS, P. (2007), “A note on convergence under income tax progressivity", Macroeconomic Dynamics, forthcoming.

PIRAS, R. (1997), “On Lucas's Model of Endogenous Growth” Economic Notes, 26, 111-134.

PSACHAROPOULOS, G, and H.A.PATRINOS (2004), "Returns to Investment in education: A further update", Education Economics 12(2), 111-134. 
ROMER, D. (1996), “Advanced macroeconomics”, New York, McGraw-Hill.

SALA-I-MARTIN, X. (1997), "I just ran two million regressions", AEA Papers and Proceedings, May.

SALA-I-MARTIN, X. , G. DOPPERLHOFER AND R.I. MILLER (2004), “A Bayesian Averaging of Classical Estimates (BACE) Approach," American Economic Review, American Economic Association, vol. 94(4), pp. 813-835, September.

SIANESI, B. and J. VAN REENEN (2003), "The Returns to Education: Macroeconomics", Journal of Economic Surveys, 17(2), pp. 157-200.

TEMPLE, J. (2000), "Growth regressions and what the textbooks don't tell you", Bulletin of Economic Research, 52, 181-205.

TOPEL, R. (1999), “Labor markets and economic growth”, in O. Ashenfelter and D. Card (eds.), "Handbook of Labor Economics", Amsterdam, North Holland.

UZAWA, H. (1965), "Optimum technical change in an aggregative model of economic growth", International Economic Review, 6, pp. 18-31. 


\section{WORKING PAPERS}

The full series of Economics Department Working Papers can be consulted at www.oecd.org/eco/Working_Papers/

591 The private internal rates of return to tertiary education: new estimates for 21 OECD countries (December 2007) Romina Boarini/Hubert Strauss.

590 Making federalism work

(December 2007) Alexandra Bibbee

589 The Wage premium on tertiary education: New Estimates for 21 OECD countries (December 2007) Hubert Strauss/Christine de la Maisonneuve

588 Enhancing the benefits of financial liberalisation (March 2007) Stefan Ide, Jens Høj, Patrick Lenain

587. Improving Incentives in Tertiary education (Marcch 2007) Jens Høj

586 Globalisation and the European Union: which countries are best placed to cope? (December 2007) David Rae, Marte Sollie

585 Primary and Secondary education in the United States (November 2007) Peter Tulip and Gregory Wurzburg

584 Financing higher education in the United States (November 2007) Peter Tulip

583 Corporate Net Lending: a review of recent trends (November 2007) Christophe André, Stéphanie Guichard, Mike Kennedy and David Turner

581. Local government finances: The link between intergovernmental transfers and net worth (September 2007) Luiz de Mello

580. Boosting Austria's Innovation Performance Improving Innovation (September 2007) Willi Leibfritz and Jürgen Janger

579. Improving Employment Prospects in the Slovak Republic: Building on Past Reforms (September 2007) Andres Fuentes

578. Improving education outcomes in the Slovak Republic (September 2007) David Carey

577. Regulatory reforms in Sweden have boosted productivity (September 2007) Espen Erlandsen and Jens Lundsgaard

576. The policy determinants of investment in tertiary education (September 2007) Joaquim Oliveira Martins, Romina Boarini, Hubert Strauss, Christine de la Maisonneuve and Clarice Saadi 
575. Product market competition in the OECD countries: taking stock and moving forward (September 2007) Jens Høj, Miguel Jimenez, Maria Maher, Giuseppe Nicoletti, and Michael Wise

574. Too little destruction too little creation: A Schumpeterian diagnosis of barriers to sustained growth in Ukraine

(September 2007) Christian Gianella and William Tompson

573. How do the OECD Growth Projections for the G7 Economies Perform? A post-mortem. (September 2007) Lukas Vogel

572. Austria's deepening economic integration with Central and Eastern Europe (August 2007) Rina Bhattacharya

571. Meeting the challenges of decentralization in France (July 2007) Stéphanie Jamet

Faire face aux défis de la décentralisation en France (juillet 2007) Stéphanie Jamet

570. Enhancing incentives to improve performance in the education system in France (July 2007) Paul O'Brien

Renforcer les incitations à une meilleure performance du système éducatif en France (juillet 2007) Paul O’Brien

569. Combating poverty and social exclusion in France

(July 2007) Stéphanie Jamet

Lutter contre la pauvreté et l'exclusion social en France

(juillet 2007) Stéphanie Jamet

568 The competition law and policy indicator (July 2007) Jens Hoj

567. Structural policies and economic resilience to shocks (July 2007) Romain Duval, Jørgen Elmeskov and Lukas Vogel

566. Family policy in Hungary: how to improve the reconciliation between work and family? (July 2007) Philip Hemmings

565. Encouraging sub-national government efficiency in Hungary (July 2007) Alessandro Goglio

564. Integration of immigrants in OECD countries: do policies matter? (July 2007) Orsetta Causa and Sébastien Jean

563. The unemployment impact of immigration in OECD countries (July 2007) Sébastien Jean and Miguel Jiménez

562. Migration in OECD countries: labour market impact and integration issues (July 2007) Sébastien Jean, Orsetta Causa, Miguel Jiminez and Isabelle Wanner

561. The internationalisation of production, international outsourcing and employment in the OECD (June 2007) Margit Molnar, Nigel Pain and Daria Taglioni 